\title{
A Greybox Hospital Information System in the Medical Center Tobruk Libya based on 3LGM
}

\author{
Mohamd Ma Abdellgoad, Moechammad Sarosa, Dachlan Harry Soekotjo \\ Student on Department of Electrical Engineering Brawijaya University Malang, Indonesia
}

\begin{abstract}
Hospital Information System this study is set out to consider the different suggested models for hospital information system and then to look at their advantages and disadvantages in comparison with other model the selected information system model. This is where this project comes in to study the current information system architecture and the quality of information system to propose a comprehensive hospital information system model to support information system managers.

They are supposed to make the right information and knowledge available to the right people, in the right place, at the right time and in the right form. To improve a HIS, its current state needs to be known. $3 L G M$ (Three-layer Graph-based model) is a structured already validated approach for modeling and analyzing HIS.

Keywords - Hospital Information System using 3LGM.
\end{abstract}

\section{INTRODUCTION}

Hospital Information Systems (HIS) is the one that supports all hospital functions and activities such as patient medical history records, checkup scheduling, administrations, chargeback and billing system, and often links to or includes clinical information systems such as Radiology Information System (RIS). This parts of HIS, which use computer system as Information and Communication Technology (ICT) is called as Computer supported part and the remainder are called Non Computer supported parts. From the beginning of a new hospital, it should be e more like whether the performance of it should be enhanced and the state of quipped with a HIS, but the question is not whether a hospital should be equipped with it or not but the art can be how the ICT tools can make a complete HIS that covering whole area of hospital or how the HIS can have an optimal speed and performance when used.

We are using the 3LGM for modeling information systems, and describe the process of modeling parts of the hospital information system we modeled the sub information systems of patients. We explain the steps of identifying the model elements and their relations as well as the analyzing capabilities of the 3LGM to answer questions about the information system.

\subsection{Problem statement:}

1. How to support Management Information System in hospital information system (HIS)?

2. What are the necessary steps to improve Hospital Information System in the Doctor data, patient data and clinical documentations in Management Information System ?

3. How to develop Management Information system in HIS be able to give valid and safe data for Doctor data , patient data and clinical documentations for the other system like DSS , TPS etc.

\subsection{Objectives of Research}

To advance the quality of information system by using 3LGM at Hospital Information System (HIS) model for Tobruk Medical Center.

\subsection{Scope of Research}

1. This research will focus on Management Information System for Doctor Data, patient data and clinical documentations.

2. The application will build a part of HIS and using PHP and MySQL.

\section{RESEARCH METHODOLOGY}

The Systems Development Life Cycle (SDLC) or software development process in systems engineering is a process of creating or altering information systems. These are models and methodologies that people use to develop the system. In software engineering, the SDLC concept underpins many kinds of software development methodologies. These methodologies form the framework for planning and controlling the creation of an information system. This part will introduce the fundamental four models (planning, analysis, design and development) of the Medical Center System that is common to all information system development projects. It 
then examines several commonly used system development methodologies that differ in their focus and approach to each of these phases.

\subsection{RESEARCH STEPS}

The goal of the research process is to produce new knowledge or deeper understanding of a topic or issue. In this broad definition, it is a necessary part of any activity, insofar as the latter becomes the object of consciousness, learning, and rationalization. The following of flow chart diagram which illustrates the concept of the initial course of study to determine the background of the research. It aims Systematic empirical investigation of quantitative properties and phenomena and their relationships.

\subsection{Domain Layer of Main Functions in Tobruk HIS}

\section{DESIGN AND IMPLEMENTATION SYSTEM}

This covers design of information system in the Medical Center of Tobruk and the main functions in the hospital. Find existed gaps in present system and then improve the system with 3LGM model for the current information system in the Medical Center. Then the main functions in the Tobruk Medical Center will be expanded to smaller functions to explain the more detailed functions in each main part.

The main function of Tobruk HIS are:

1. Patient Care

2. Supply Management, schedulling and resources management

3. Hospital Administration

4. Hospital Management

a. Patient care comprises: Patient admission, Decision making planning and organization of patient treatment Order entry, Execution of diagnostic, therapeutic and nursing procedures, coding of diagnoses and procedures, Patient discharge and transfer to other institutions.

b. Supply Management, schedulling and resources management the hospital must offer sufficient and wellorganized resources for patient care. This true for wards (ward management), outpatient units (outpatient management), and service units (department management). Efficient process organization is extremely important for hospitals for example, in outpatient units or service units, and it can be supported, for example, by providing working lists for individual staff members, by issuing reminders about appointments, or by visualizing actual process flow. The HIS must be able to support communication between all persons involved in patient care.

c. Hospital Administration In this section the third and last of the top most hospital functions performed at Hospital administration and its sub-functions Patient management Archiving of patient information Quality Management Controlling Cost and results accounting and Financial accounting' are described. Also all the entity types used and/or updated by these hospital functions are described.

d. Hospital Management decides on questions of fundamental importance for the hospital development (hospital goals, strategic decisions, personnel decisions and decisions about budget, investments, and key treatments). Hospital management has to focus on high quality of patient care taking into account economic as well as legal and other requirements. Budget Consists of all planned costs and revenues business strategy defines the hospital's long-term strategic goals. Strategic information management plan is a strategic plan which gives directives for the construction and Development of a Hospital Information System.

\subsection{Modeling the information in a 3LGM model}

In the following I will explain how the modeling of the departments was done on the logical and physical tool layer. On the logical tool layer all the application components used at the departments in are modeled. First all the computer-based and paper-based application components were added to the model. As no paper based application components exist at only computer based were modeled. The physical tool layer of the department displays all physical data processing components 'Physician' and Nurses are seen as physical data processing components, too, because the physician dictates medical admission with the 'Digital Dictation Devices' and the nurse writes it down afterwards. There are also many inter layer relationships. In the following the inter layer relationships between the logical tool layer and the physical tool layer are described. 'Take Care' and 'Orbit' are installed on all kinds of PCs (PC office, PC ward, PC OR and medication PC) The data generated by 'Digital Dictation Devices' is processed using the application component Digital Dictation on the Servers SLL.

\subsection{Use case Diagram}

a. Patient queue Enables the reception of the order of patient files to enter it all the patients will be presented by their presence dates and times arranged so be brief reception on patients who still on the waiting list to enter

b. Patient Admission one new profile will be created for him/her. In fact, this Module helps in registering information about patients and handles patient's query. A unique ID is generated for each patient after 
registration. This helps in implementing customer relationship management and also maintains medical history of the patient.

c. Room and lab reservation Must to patient bring ID card then show ID card to Staff after that can staff do Manage reservation for him / her, by login or create a new room if first time to patient also can do reserve for Lab.

d. Doctor Examination System The patient's is subject to scrutiny by a specialist doctor and then take the appropriate decision for the patient or to create a prescription or send the patient to the lab to take some tests or temporary residence which is advised to book a new room for the patient.

\subsection{Hospital Information System Database}

Part covers database of information system in the Medical Center of Tobruk and described is the implementation and integration of medical record and database into an existing hospital information system profile. This complete database integrated data from hospital functions like data obtained at patient registration, Patient queue, outpatient visits and tests, inpatient admission historical data. This permitted immediate access to patient data from any hospital information system terminal, immediate retrieval for reports queries, statistical analysis and the electronic transfer to others sections.

a. Patient admission When patients arrive at the hospital, and during their course of their stay, they can be transferred between different units, sent to the operating room for surgery, sent to the floor for recovering or undergo other procedures to better describe these events.

b. Patient queue Notify additional staff if patient wait times exceed pre determined criteria monitors patient wait times and determine the status of copy collections as well as identifies patients who have updated their demographic and insurance information during the check in process. Additionally, your staff can determine whether documentation and or other EHR forms have been signed. Queue Navigator can also.

c. Clinical Documentation improvement programs formed in an effort to work with care providers to appropriately reflect the quality of patient care while increasing accuracy in coding and reporting. Health information management (HIM) and clinical staff form the core of CDI programs.

d. Create Recipe The findings confirm the need for clear definitions of role and responsibilities together with closer coordination of food provision and nutritional care at all levels within hospital trusts. It is that food provision should be managed as an integral component of clinical care.

e. Create room the following tables show the creation of new rooms in the system database of hospital Tobruk Medical Center and include nine tables.

f. Create Lap Reservation The following tables show the creation of Lab Reservation in the system database of hospital Tobruk Medical Center and include eight tables.

\section{FIGURES AND TABLES}

Table 1 Comparison 3LGM with other models

\begin{tabular}{|l|l|l|}
\hline \multicolumn{1}{|c|}{ Requirement } & 3LGM & \multicolumn{1}{c|}{ Other models } \\
\hline $\begin{array}{l}\text { 1.Should be possible to model enterprise function and the tools } \\
\text { supporting them }\end{array}$ & $\sqrt{ }$ & $\begin{array}{l}\text { Functional model (only functions) } \\
\text { technical model (only supporting } \\
\text { tools) }\end{array}$ \\
\hline $\begin{array}{l}\text { 2. Relationships between both the enterprise function and the tools } \\
\text { (r1) should be able to be modeled. }\end{array}$ & $\sqrt{ }$ & \\
\hline $\begin{array}{l}\text { 3. Inter working of functions as well as communication between the } \\
\text { tools in (r1) should be able be modeled whereby the relationship of } \\
\text { (r4) have to be taken into account. }\end{array}$ & $\sqrt{ }$ & \\
\hline $\begin{array}{l}\text { 4. If an entity types is stored in one application but the function } \\
\text { which needs it is supported by another communication is needed. }\end{array}$ & $\sqrt{ }$ & \\
\hline
\end{tabular}




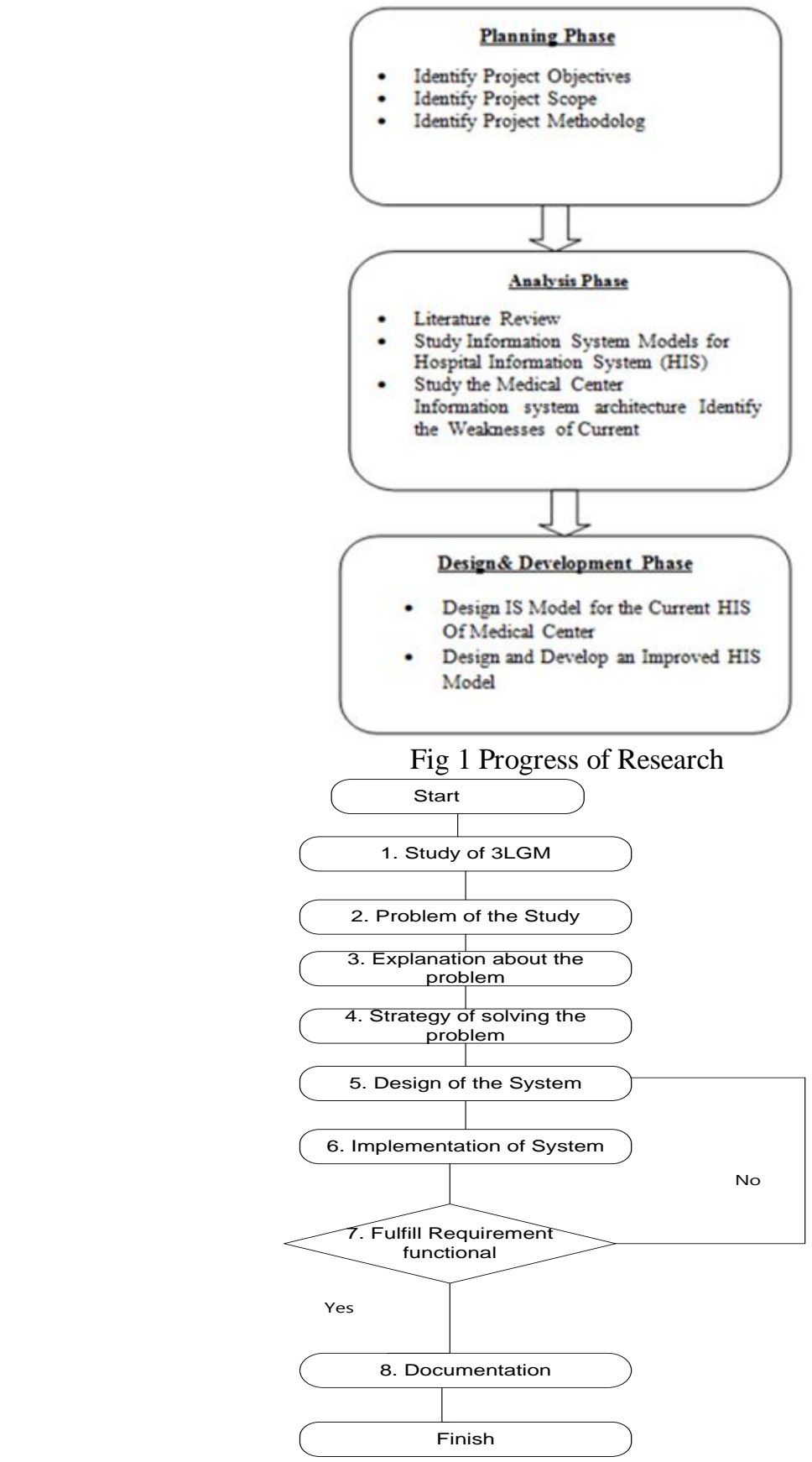

Fig 2 Flowchart of the Research
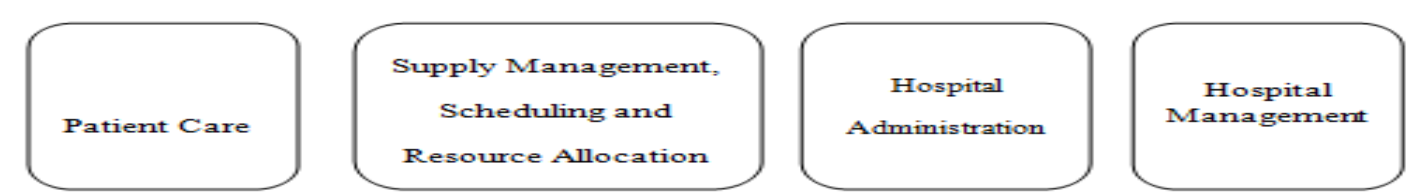

Fig 3 Domain Layer of Main Functions in Tobruk HIS 


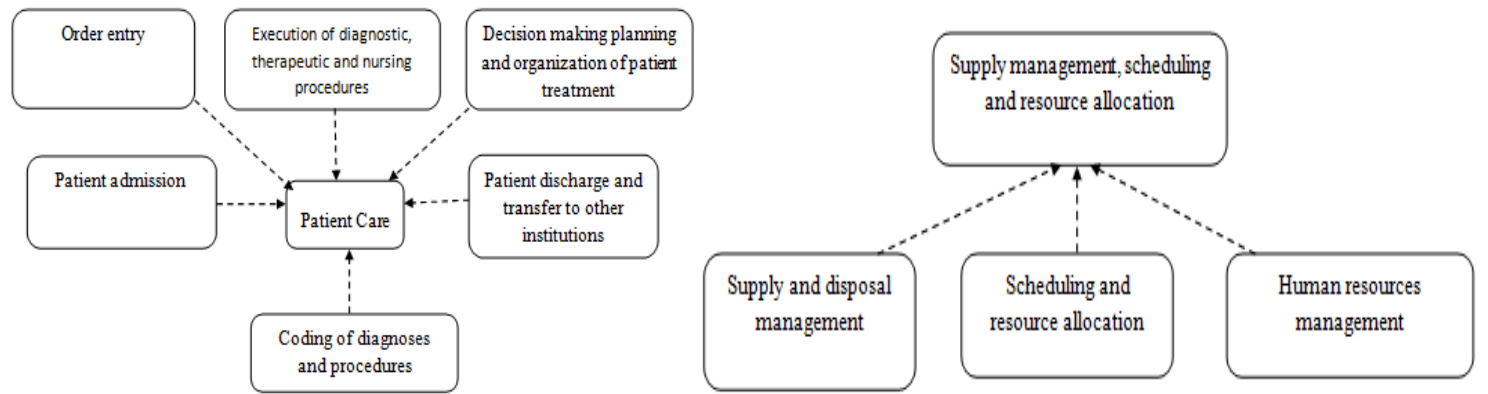

Fig 4 Reference Doman Layers 3LGM of Patient Care Fig 5 domain layers Supply and disposal management

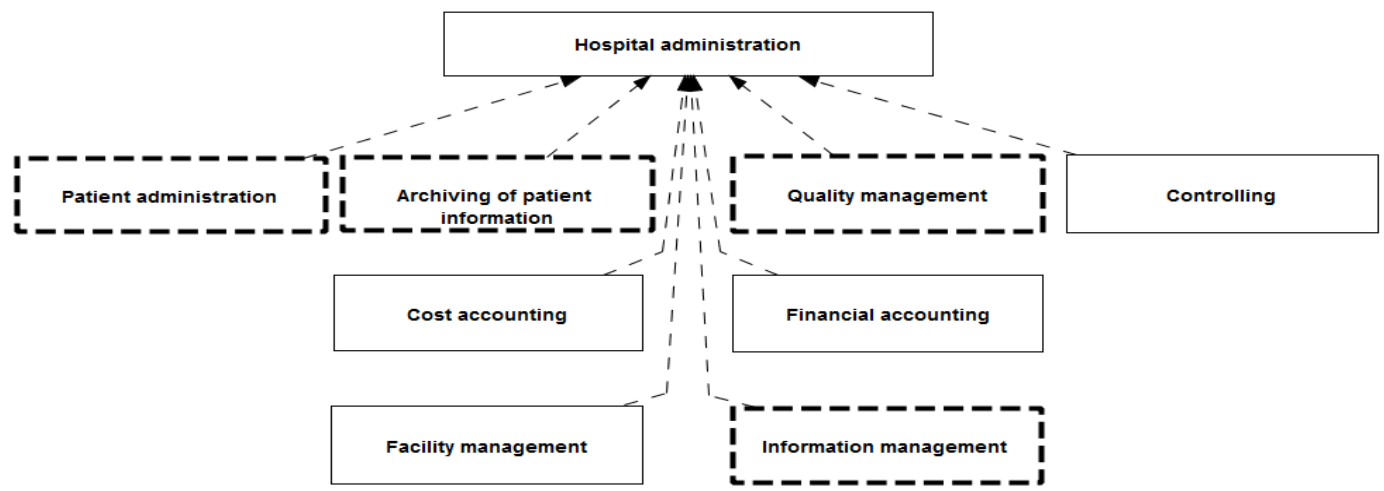

Fig 6 Doman layer of Hospital Administration

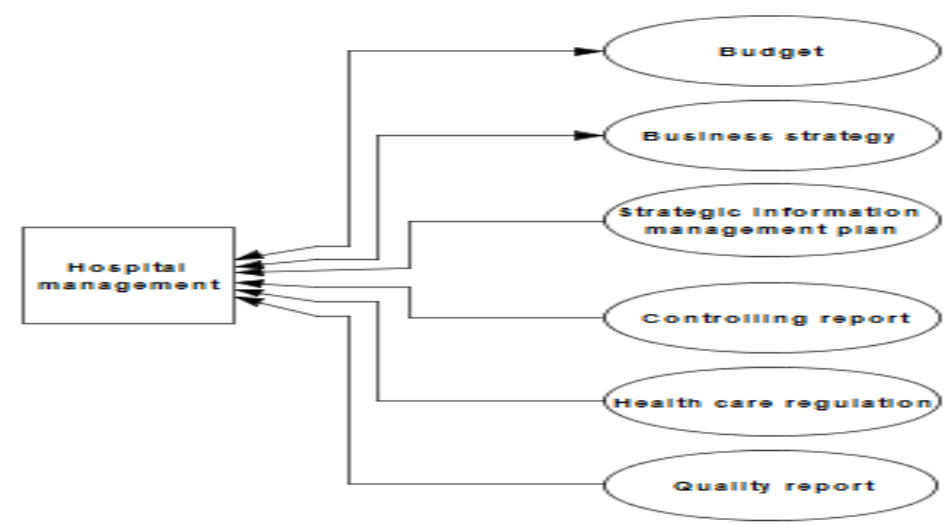

Fig7 Doman Layers 3LGM of of Hospital Management

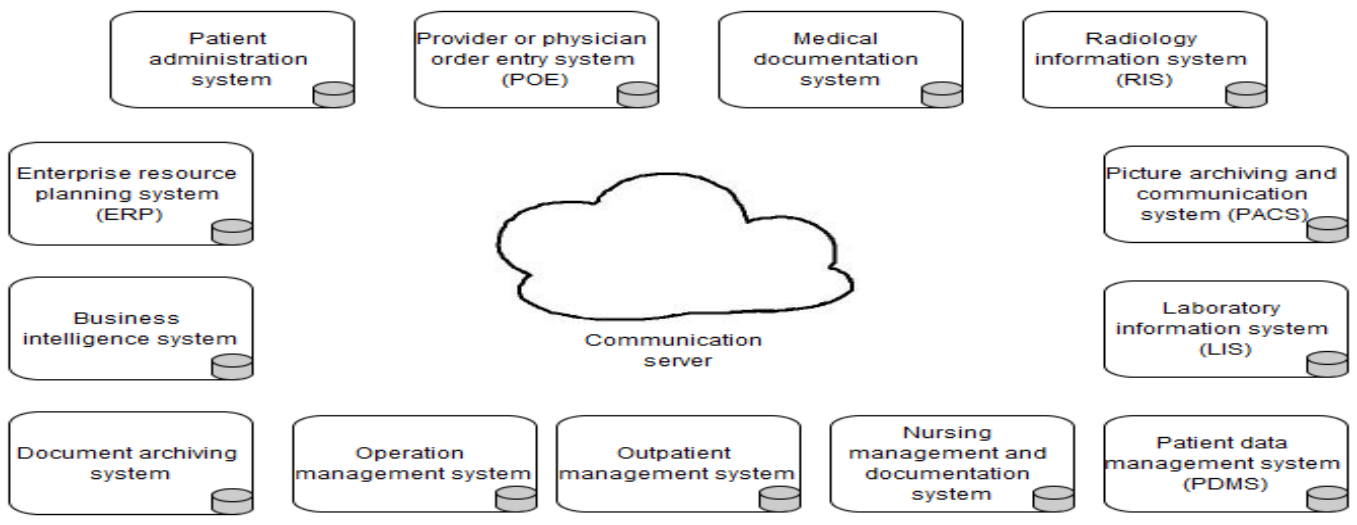

Fig1 Logical tool layer of Medical Center 


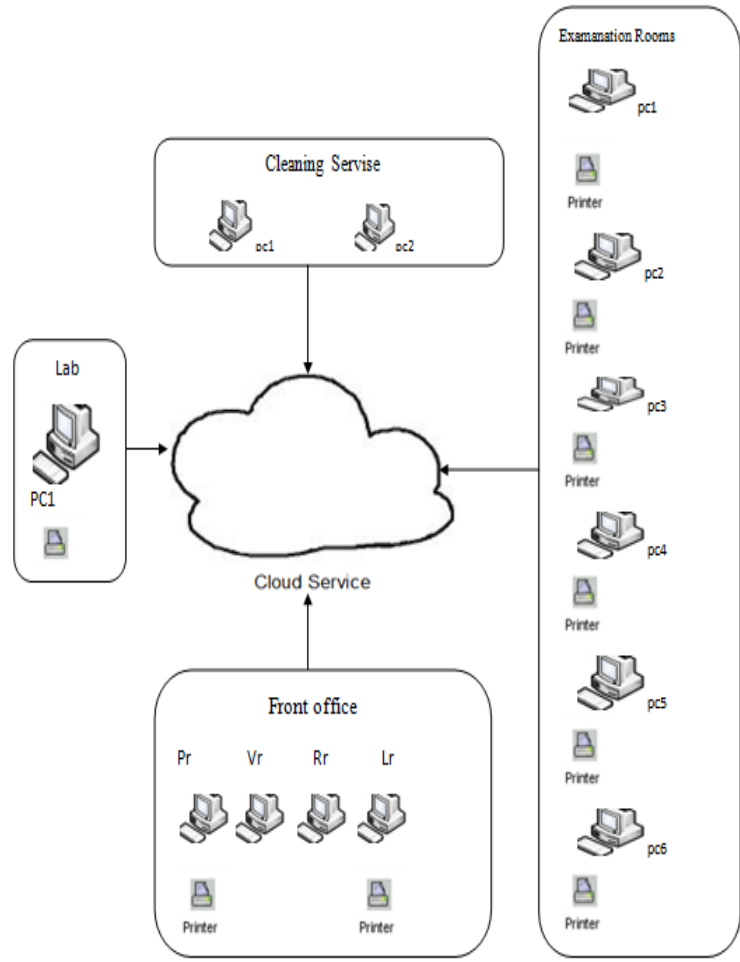

Fig 9 physical tool layer of Medical Center

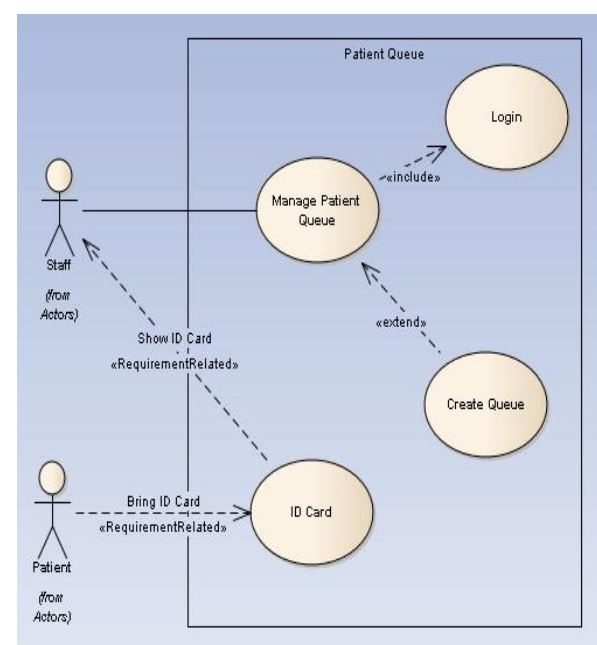

Fig 10 Use case for patient queue

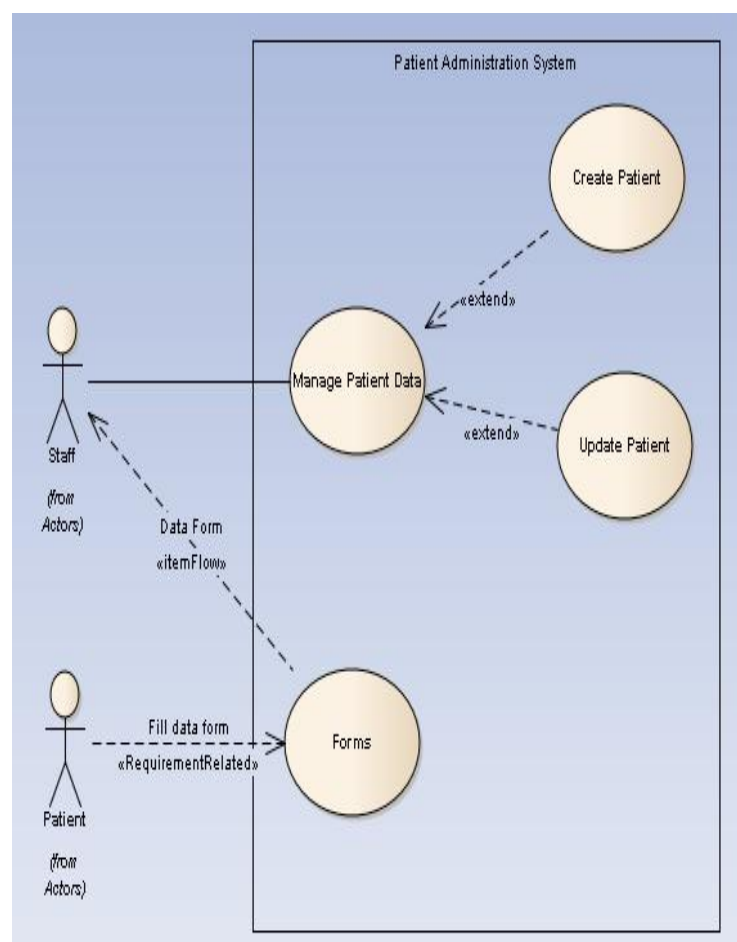

Fig11 use case patient Admission activity

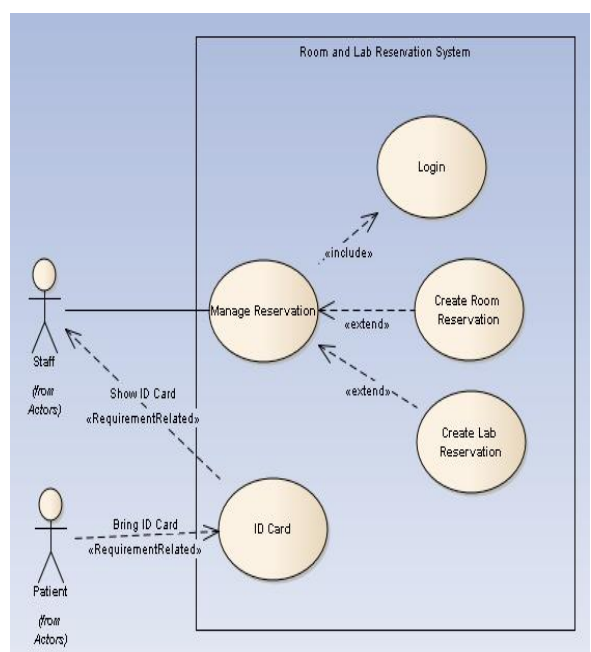

Fig 12 Use case for Room and lab reservation 


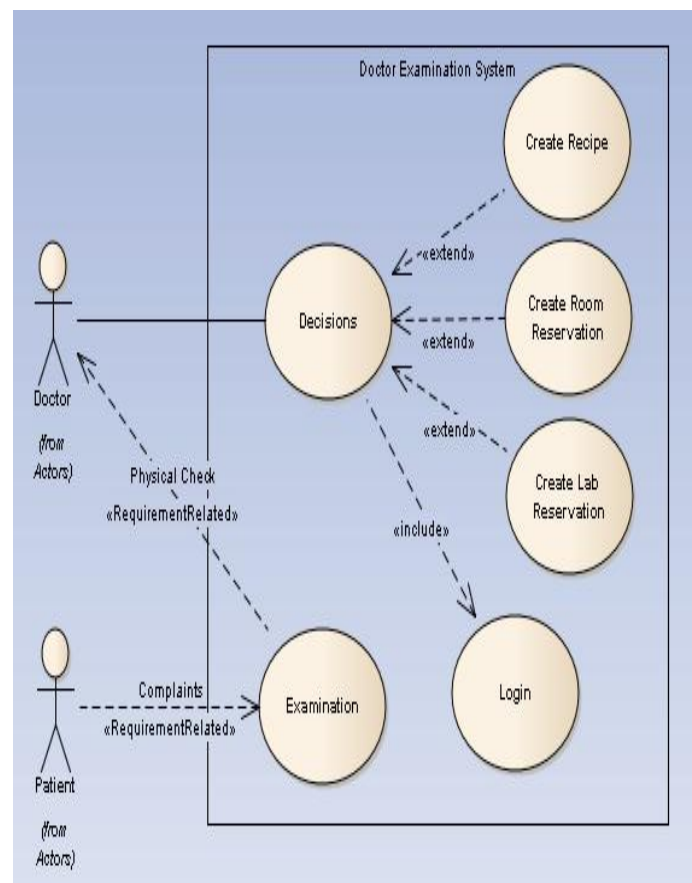

Fig 13 Use case for Doctor Examination System

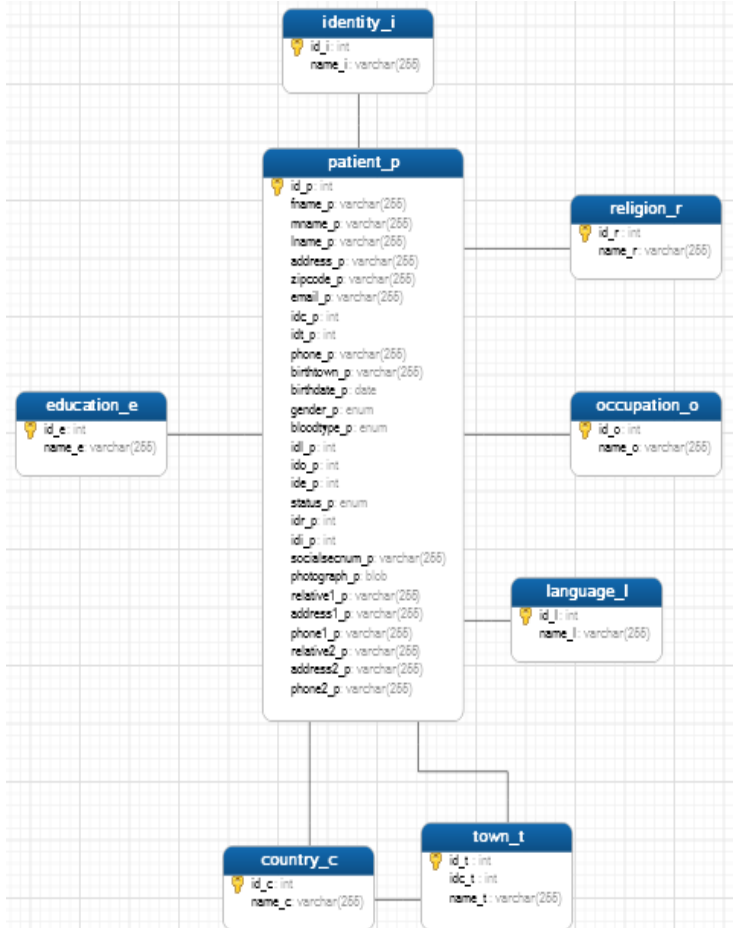

Fig14 Database Hospital of Patient Admission

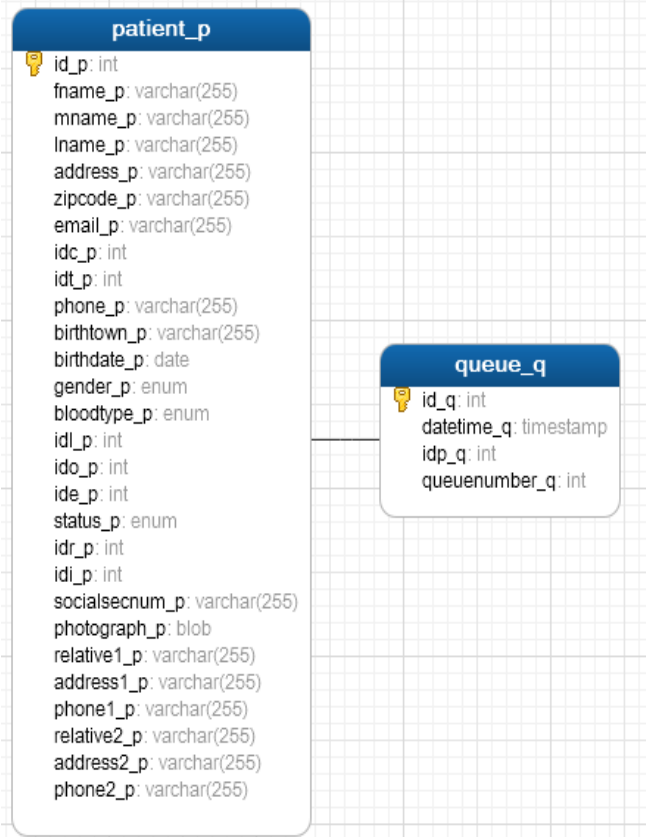

Fig15 Database Hospital of patient queue

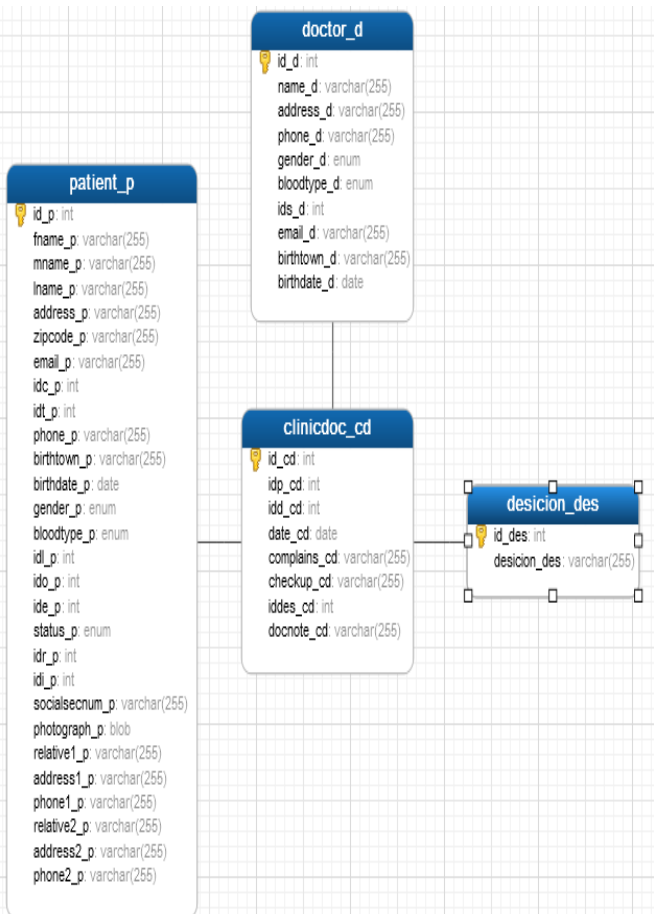

Fig16 Database Hospital of Clinical documentation 


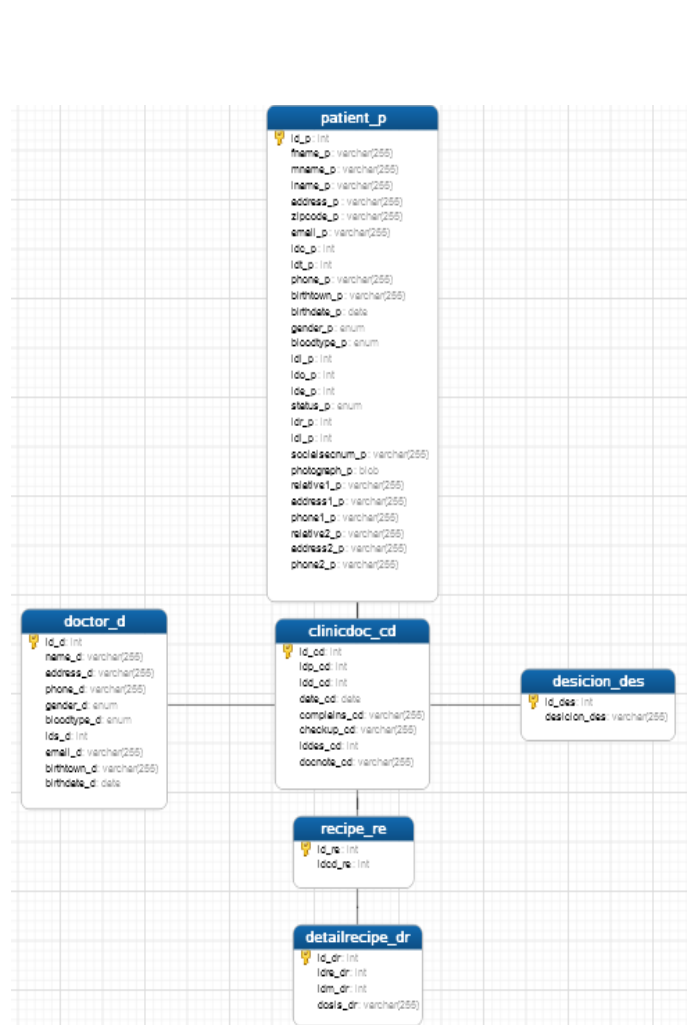

Fig 17 Database Hospital of Create recipes

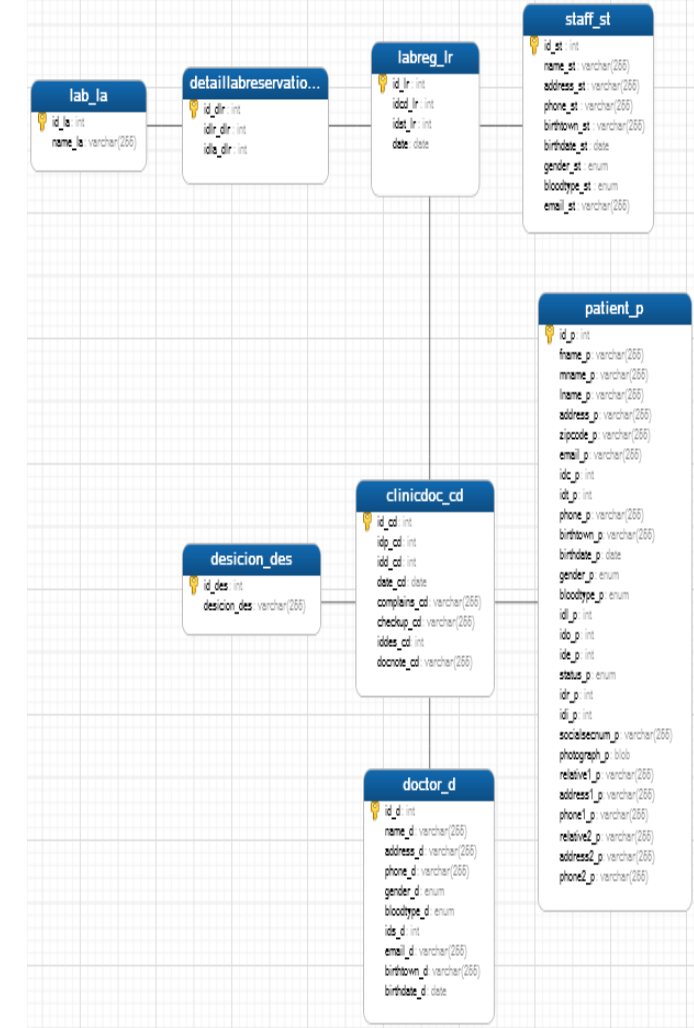

Fig19 Database Hospital of Create Lab Reservation

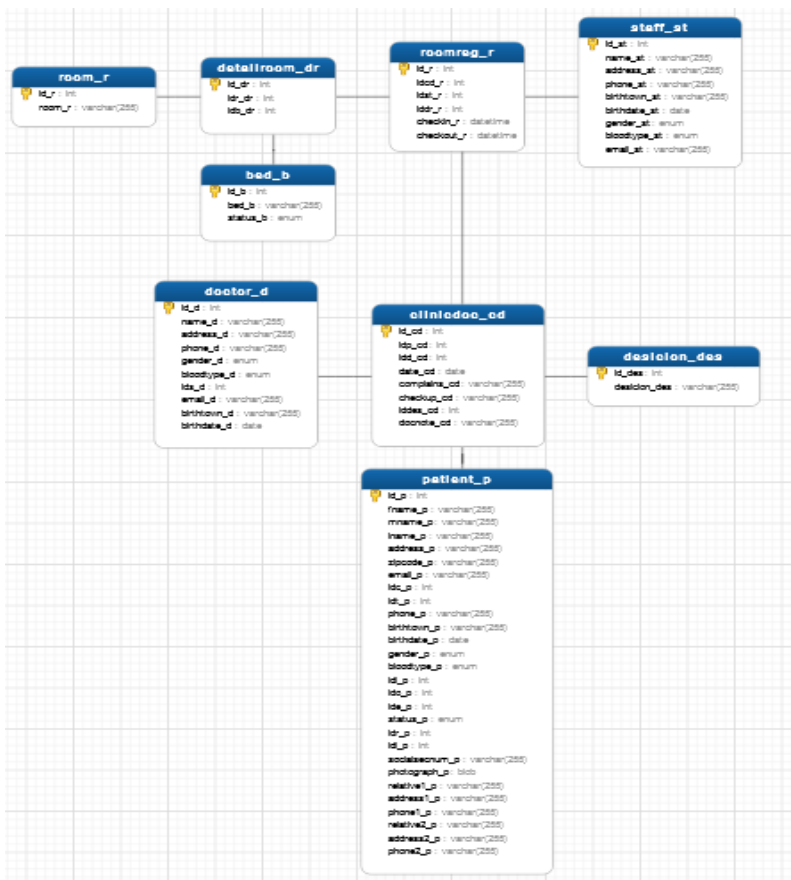

Fig18 Database Hospital of Create Room

\section{CONCLUSION}

The main focus of this project is to develop an information system model for Hospital Medical Center in Tobruk for Patient data, Doctor data and Clinical Documentation also support Management information system in Hospital information system.

Aspirations the 3LGM cannot represent the entity types. Information has to be modeled as entity types used by enterprise functions thus supporting entity types is a main concern for information managers 3LGM.

All tasks have been completed successfully. the information system model will be developed and implement. 
All the constraints and challenges that are faced during the project development have been resolved. Information System Meta Model for Hospital Information System will benefit information system managers to manage information systems and hospital managers to have a blueprint to supervise the information systems and utilize them through the mission and goals of their organization.

\section{REFERENCES}

[1] Haux Reinhold, Winter Alfred, Brigl Birgit (2004). Strategic Information Management in Hospitals: An Introduction to Hospital Information Systems. Springer. 63-73

[2] Haux R., Michaelis J (1997). nvestitionsschema zur Inforamtion sverarbeitung in Krank enhausern (investment scheme for information processing in hospitals).Das Krankenhaus. 7, 425-26.

[3] Hubner-Bloder Gudrun, Ammenwerth Elske, Brigl Birgit, and Winter Alfred (2005), et al Specification of a Reference Model for the Domain Layer of a Hospital Information System. In: Engelbert Rolf, Geissbuhler A., and Lovis C. Connecting Medical Informatics and Bio-informatics. IOS Press. 497-502

[4] Ammenwerth E., Buchauer A, and Haux R (2002). A Requirements Index for Information Processing in hospitals. Methods of Information in Medicine. 41 (4), 282-8. The requirements index is available at: http://www.umit.at/reqhis. Azizul Rusmadi Bin Abdul Rahman (2006).

[5] Wendt T., Haber A., Brigl B., and Winter A (2004). Modeling Hospital Information Systems (Part 2): sing the 3LGM for Modeling Patient Record Management. Methods Info Med. (43), 256-267.

[6] A. Brookstone, "Electronic medical records: Creating the environment for change," british olumbia medical journal, vol. 46, pp. 233-235, 2004.

[7] D. Garets and M. Davis,"Electronic medical ecords vs. electronic health records: yes, there is a difference," A HIMSS Analytics White Paper. Chicago, IL: HIMSS Analytics, 2005.

[8] Alvarez, R. (2002). The promise of e-Health a Canadian perspective. eHealth International, (1),4.

[9] Bath, P. A. (2008). Health informatics: current issues and challenges. Journal of Information Science, 34(4), 501-518.

[10] Engelbrecht Rolf, Geissbuhler A., Lovis C (2005). Connecting Medical Informatics and Bio-informatics: Proceedings of MIE2005: the XIXth International Congress of the European Federation for Medical Informatics. IOS Press. 